\title{
Çocuklarda ve Adölesanlarda Ağız Sağlığına Bağlı Yaşam Kalitesinin Değerlendirilmesi
}

\author{
Ayşegül YARAN*, Edibe EGİL**
}

\begin{abstract}
$\ddot{O} \mathbf{z}$
Yaşam kalitesi kişinin kendini sosyal, psikolojik ve fizyolojik olarak iyi hissetme halidir. Kişinin fiziksel sağllğından, psikolojik durumundan, sosyal ilişkilerinden ve çevrenin sosyal özelliklerinden etkilenir. Sağlık alanında verilen hizmetlerin değerlendirilmesinde yaşam kalitesi üzerine yapılan araştırmalar önem kazanmaktadır. Hastalık durumunun ve hastalık tedavilerinin birey üzerindeki etkileri sağlık protokollerinin düzenlenmesinde rol oynar. Ağız sağlığı da genel sağlı̆̆ın ayrılmaz bir parçasıdır. Diş çürüğü, travma ve maloklüzyon gibi oral problemlere çocukluk döneminde rastlanırken adölesan ve yetişkinlik döneminde de etkileri devam edebilmektedir. Ağız sağlığının kötü olmasına bağlı olarak çocuklarda ve adölesanlarda estetik kaygı, konuşma bozuklukları ile birlikte yaşanan ağrıya bağlı olarak uyku, yemek yeme problemleri ve konsantrasyonda zorluk görülmektedir. Ağız sağlı̆̆ının iyi olması, bireyin günlük aktivitelerini rahatlıkla idame ettirebilmesine katkıda bulunur, bununla birlikte topluma yaratıcı bir şekilde katkıda bulunması konusunda motive olmasına yardımcı olur. Ağız sağlığına bağlı yaşam kalitesinin değerlendirilmesinde çok sayıda ölçek kullanılmaktadır. Bu derlemenin amacı çocuk ve adölesanlarda ağız sağ lığına bağlı yaşam kalitesini ve ağız sağlığına bağlı yaşam kalitesini değerlendirmede kullanılan ölçekleri değerlendirerek bir araya getirmektir.
\end{abstract}

Anahtar Kelimeler: Yaşam kalitesi, diş çürükleri, adölesan, çocuk, ağız sağlığı.

\section{Derleme Makale (Review Article)}

Geliş / Received: 09.09.2020 \& Kabul / Accepted: 31.03.2021

DOI: https://doi.org/10.38079/igusabder.792610

* Diş Hekimliği Öğrencisi, Beykent Üniversitesi, Diş Hekimliği Fakültesi, İstanbul, Türkiye, E-posta: aysegulozyeryaran@gmail.com ORCID https://orcid.org/o000-0003-4761-263X

** Dr. Öğr. Üyesi, İstanbul Gelişim Üniversitesi, Diş Hekimliği Fakültesi, Pedodonti Anabilim Dalı, İstanbul, Türkiye, E-posta: eegil@gelisim.edu.tr ORCID https://orcid.org/0000-0003o889-0223 


\title{
Assessing Oral Health-Related Quality of Life in Children and Adolescents
}

\begin{abstract}
Quality of life is a state of social well-being, psychologically and physiologically. It's affected by a person's physical health, psychological state, social relationships and social characteristics. Searches on quality of life gain importance in evaluating the services provided in the field of health. The effects of disease state and disease treatments on the individual play a role in the regulation of health protocols. Oral health is also an integral part of general health. Oral problems such as tooth decay, trauma and malocclusion are encountered in childhood; Its effects may continue in adolescence and adulthood. Due to poor oral health, difficulty concentrating and painrelated sleep problems are observed. Good oral health contributes to the ability of the individual to easily maintain their daily activities. It also helps them to be motivated and concentrated to contribute creatively to society. A large number of scales are used to evaluate the oral healthrelated quality of life. The aim of this review is to assess oral health-related quality of life in children and adolescents and bring together the scales used to evaluate the oral health-related quality of life.
\end{abstract}

Keywords: Quality of life, dental caries, adolescent, child, oral health.

\section{Giriş}

Dünya Sağlık Örgütü (DSÖ)'ne göre yaşam kalitesi bireyin sağlıklı olma durumu ile birlikte fiziksel, zihinsel ve sosyal refah durumu olarak tanımlanır ${ }^{1}$. DSÖ’ye göre yaşam kalitesinin tanımını genişletecek olursak "Yaşam kalitesi bir bireyin, içinde yaşadığ kültür ve değer sistemi içinde hedefleri, beklentileri, standartları ve endişeleri ile ilgili olarak yaşamdaki konumlarına ilişkin algısıdır. Kişinin fiziksel sağlı̆̆ından, psikolojik durumundan, bağımlılık düzeyinden, sosyal ilişkilerinden ve çevrelerinin belirgin özellikleriyle ilişkilerinden karmaşık bir şekilde etkilenen geniş kapsamlı bir kavramdır². Ağız sağlığı iyi olan kişiler daha iyi bir yaşam kalitesine sahiptir ve kötü ağız sağlığına sahip bireylere göre daha az hastalanırlar3. Ağız sağlığının iyi olması, bireyin genel iyilik haline katkı sağlamasının yanı sıra kişinin yemek yeme, konuşma, gülümseme ve hatta topluma yaratıcı bir şekilde katkıda bulunma gibi işlevleri yerine getirmesini sağlar. Artık günümüzde anlaşılmıştır ki ağız sağlığı genel sağlık ve iyilik hali ile ayrılmaz bir bütündür4. 


\section{Çocuklarda ve Adölesanlarda Ağız Sağlığına Bağlı Yaşam Kalitesi}

İyi ağız sağlığı genel sağlı̆̆ın ayrılmaz bir bileşenidir. Locker5 ağız sağlığını "Bireylerin rahatsızlık, sıkıntı veya utanç hissetmeden yemek yemelerine, konuşmalarına ve sosyalleşmelerine olanak sağlayarak genel fizyolojik, psikolojik ve sosyal iyilik hallerine katkıda bulunan ağız dokularının bütünlüğü” olarak tanımlamıştır. Çocuklar erken çocukluk dönemindeki kötü ağız sağlığı sebebiyle yemek yeme güçlüğü, konuşmada zorluk, ağrı nedeniyle uyku problemleri ve enfeksiyonun yüze yayılması sonucu yüzün beklenmedik görünüşü sebebiyle zorluk yaşayabilir ve bunların ömür boyu sürebilecek etkileri sosyalleşmeyi riske atabilir ${ }^{6}$. Erken çocukluk döneminde verilen ağız sağlı̆̆ı ve hijyen uygulamaları, kişinin hayatı boyunca iyi bir ağız sağlı̆̆ı için temel sağlar.

\section{Çocuklarda Erken Çocukluk Çağı Çürüklerinin Değerlendirilmesi ve Yaşam Kalitesine Etkisi}

Diş çürüğü, dünya çapında küçük çocukların \%60-9o'ını etkileyen, çocukluk çağının en yaygın görülen kronik hastalığıdır. Tedavi edilmeyen diş çürükleri ağı, diş ve çene bölgesinde kronik enfeksiyonlara ve ağrılara neden olur. Bunun sonucunda düşük özgüven, beslenme bozuklukları ve yetişkinliğe kadar devam eden eğitim hayatında konsantrasyonunun azalmasına neden olabilir. 2010'da yapılan Küresel Hastalık Yükü çalışmasında; daimî dişlerdeki tedavi edilmemiş diş çürüklerinin incelenen 291 hastalık arasında en yaygını olduğu ve dünya çapında ciddi bir sağlık yükü oluşturduğu bildirilmiştir7. 2017'de yapılan Küresel Hastalık Yükü çalışmasına göre 531 milyon çocuğun süt dişlerinde çürük sorunu yaşadığı tahmin edilmektedir8. Çocuklar diş çürüklerine ek olarak diş çıkarma, travma ve maloklüzyon gibi oral problemler yaşamaktadır. Ancak diş çürükleri gibi klinik parametreler çocukların yaşam kalitesi üzerine etkisini ölçmemektedir. A ̆ğı sağlı̆̆ının yaşam kalitesi üzerine etkisini ölçmek için tasarlanmış çeşitli ölçekler bulunmaktadır.

Çocuk ve Adölesanlarda Ağız Sağlığına İlişkin Yaşam Kalitesini Değerlendirmede Kullanılan Ölçekler

Çocuklarda Ağız ve Diş Sağhğı ile İlgili Yaşam Kalitesi Anketi (Child Oral Health Quality of Life Questionnaire- COHQoL): Toronto'da bir ekip tarafindan 6-14 yaş arası çocuklarda ağız sağlığına bağlı yaşam kalitesini değerlendirmek üzere tasarlanmıştır9. Sağlık çalışanları, ebeveynler ve çocuklardan alınan bilgiler ile 
geliştirilmiştir. Klinik çalışmaların değerlendirilmesinde bir sonuç ölçüsü olarak kullanılmak üzere geliştirilmiştir ${ }^{10}$. Ölçekler; 6-7, 8-10, 11-14 yaş çocuklar için farklı olarak tasarlanmıştır. Küçük yaş grupları için Ebeveyn-Bakıcı Algı Anketi (ParentalCaregiver Perceptions Questionnaire/ PCP-Q) ve daha büyük yaştaki çocuklar için Çocuk Alg1 Anketinden (Child Perceptions Questionnaire/ CP-Q) meydana gelmiştir. 36 sorudan oluşan ölçekte; diş çürükleri, maloklüzyonlar, dudak damak yarıkları ve diğer orofasiyal anomaliler dahil olmak üzere pek çok orofasiyal rahatsızlık değerlendirlir.

Çocuk Algı Ölçeği 8-1o (Child Perception Questionnaire 8-1o): Çocuk Alg1 Ölçeği 8-10, Kanada'da Jokovic ve arkadaşları tarafından 2004 yılında geliştirilmiştir. Çocuk algı anketinin 2 versiyonundan birisidir; 8-10 yaş arası çocuklarda fonksiyonel, duygusal ve sosyal değerlendirmeyi hedefler ${ }^{10} .25$ maddeden oluşur ve bu maddeler doğrudan çocukların değerlendirmesine yöneliktir. 4 farklı sağlık alanını değerlendirir: Oral semptomlar, fonksiyonel sinırlamalar, duygu durumu, sosyal iyilik hali. Maddeler son 4 hafta hedeflenerek cevaplanır. Her bir madde likert ölçeğine göre (o-4 arası) puanlanan yanıtlar şu şekildedir: Asla: o puan; Bir veya iki kez: 1 puan; Bazen: 2 puan; Genellikle: 3 puan; Her gün veya neredeyse her gün: 4 puan ${ }^{11}$. 2019'da Çalık Yılmaz ve Alaçam $^{12}$ tarafından yapılan ölçeğin Türkçe’ye adaptasyonu yapılmıştır.

Çocuk Algı Ölçeği 11-14 (Child Perception Questionnaire 11-14): Çocuk Algı Ölçeği 11-14, Jokovic ve arkadaşları ${ }^{10}$ tarafından 2004 yllında geliştirilmiştir ve çocuklarda ağız sağlığına bağlı yaşam kalitesinin değerlendirmesi için geliştirilen ilk ölçeklerdendir. Yaş aralığı 11-14 olan çocuklarda fonksiyonel, duygusal ve sosyal durumu değerlendirmeyi hedefler. Otuz dokuz maddeden oluşur. Son 3 ay hedeflenerek yöneltilen sorular likert ölçeği kullanılarak cevaplanır: "Hiçbir zaman" = o; "Bir veya iki defa" = 1; "Bazen" = 2; "Sıklıkla" = 3; "Her zaman" = 4. 2015 yılında Bekiroğlu13 ve arkadaşları tarafından Türkçe geçerlik çalışması yapılmıştır.

\section{Ebeveyn Algı Ölçeği (Parental-Caregiver Perceptions Questionnaire- P-} CPQ): Ebeveyn Algı Ölçeği, dental, oral ve orofasiyal sorunları değerlendirmek üzere Jokovic ve arkadaşları10 tarafından 2004 yılında tasarlanmıştır. Çocukların ağız sağlığı ile ilgili yaşam kalitesine ilişkin ebeveyn-bakıcı algısını üzerinden ölçmeyi hedefler. Çocuklardan elde edilen bilgileri tamamlaması amaçlanmıştır ${ }^{14}$. P-CPQ, 31 maddeden oluşur: Oral Semptomlar (6 madde), Fonksiyonel Sinırlamalar (7 madde), Duygusal İyilik Hali (8 madde) ve Sosyal İyilik Hali (10 madde). Soruların son 3 ayda meydana 
gelen olaylar göz önünde bulundurularak cevaplanması istenir. 4 puanlık Likert ölçeği (o-3 puanlı) “o = Hiç”, “1 = Bir-iki kez”, “2 = Bazen”, “3 = Sıllıkla” ve “4 = Her gün veya neredeyse her gün" kullanılarak değerlendirilir.

Çocuklarda Ă̆gz Sağlığının Günlük Hayata Etkisini Ölçen Indeks (Child Oral Impact on Daily Performance-Child-OIDP): Locker tarafından ileri sürülen ${ }^{10}$ ve Dünya Sağlık Sakatlıklar, Yetersizlikler ve Engellilikler Sınıflandırmasından uyarlanan ağız sağlığı modelinden geliştirmiştir. İndeks yalnızca yetersizlik ve engellilik ile eşdeğer olan büyük etkileri ölçer. Child-OIDP çocuklardan ve pedodontistlerden gelen bilgiler kullanılarak kullanılan dil, dâhil edilen performanslar, soru sayısı ve yanıt şekline dikkat edilerek Gherunpong ve ark. ${ }^{15}$ tarafından OIDP indeksinden geliştirilmiştir. Child-OIDP, 11-12 yaş çocuklarda anket şeklinde uygulanabilir. Sekiz performans içerir: Yemek yeme, konuşma, ağız temizliği, uyuma, duygu, gülümseme, çalışma ve sosyal etkileşim ${ }^{16}$. Yanıtların değerlendirilmesinde 4 puanlık likert ölçeği (o-3 puanlı) kullanılır. Çocuk her performans için etkinin sıklığını (o-3) ve şiddetini (o-3) puanlar. 2008 yılında Türkçe’ye çevrilmiş ve 2020 yılında Peker ve arkadaşları ${ }^{17}$ tarafından Türkçe geçerlik çalışması yapılmıştır.

Çocuk Ăğz Să̆h̆̆ı Etki Profili (Child Oral Health Impact Profile/COHIP Child Oral Health Impact Profile Preschool Version/COHIP-PS): Sağlık çalışanları, ebeveynler ve çocuklardan alınan bilgiler kullanılarak Broder ve arkadaşları ${ }^{18}$ çalışmalarıyla OHIP modifiye edilerek 2007 yılında COHIP oluşturulmuştur. Ağız Sağlı̆̆ Etki Profili, oral bozuklukların sosyal etkisinin ayrıntılı ölçümü için güvenilir ve geçerli bir araç sunar. Yaş aralığ 8-15 olan çocuklar için kullanıma uygundur ${ }^{19}$. Otuz dört madde ve beş alt ölçekten oluşur: Ağız sağlı̆̆ı, fonksiyonel iyilik hali, sosyal-duygusal iyilik hali, okul çevresi ve kişinin öz saygısı ${ }^{18}$. Yanıtların değerlendirilmesin likert ölçeği kullanılmaktadır. Ayrıca COHIP'in, diş çürümesi deneyimlerine ve görünüm hakkındaki algılarına bağlı olarak gruplar arasında ayrım yapabildiği de gösterilmiştir. Bu nedenle yüksek oranda diş problemi olan çocuk popülasyonunu değerlendiren çalışmalar için uygundur. Ölçeğin 19 sorudan oluşan kısa şekli COHIP-SF, Broder ve arkadaşları²0 tarafından 2012 yılında geliştirilmiştir.

Ăğz Sağh̆ğı Sonuçları Skalası-5 (Scale of Oral Health Outcomes-5 / SOHO5): Beş yaş çocuklarında diş çürüklerinin psikolojik, sosyal ve eğitimsel etkilerini ölçmek amacıyla Tsakos ve arkadaşları tarafından geliştirilmiştir. Ölçeğin ilk bölümü diş ağrısı 
deneyimi ve hissettirdiklerini değerlendiren sorulardan oluşur. Ardından çocuklara günlük aktiviteleri ile ilgili oral açıdan herhangi bir zorluk yaşayıp yaşamadıkları sorulur. Bu sorular: Yemek, içmek, konuşmak, oynamak, gülümsemek (dişleri ağrıttığı için), gülümsemek (dişlerin görünüşünden dolayı) ve uyumaktır. Yanıtlar şu şekildedir: o (hayır), 1 (az) ve 2 (çok).Yedi maddeye verilen yanıtlar bir araya getirilerek SOHO-5 puanı oluşturulur'21.

\section{Erken Çocukluk Ăğz Să̆h̆ğı Etki Ölçeği (Early Childhood Oral Health} Impact Scale-ECOHIS): ECOHIS 6 yaşından küçük çocuklarda kullanılmak üzere Pahel ve arkadaşları ${ }^{22}$ tarafından 2007 yaşında geliştirilmiştir. Ağız ve diş sağlı̆̆ sorunlarının çocuklar ve aileleri üzerindeki etkisini belirlemek için ebeveynlerin verdiği cevaplar değerlendirilir. ECOHIS, aile ve çocuk etki kısmı olarak 2 bölüm ve toplam 13 maddeden oluşur. Çocuk etkisi bölümünde dört tanımlayıcı alan semptomlar (1 soru), fonksiyonlar (4 soru), psikoloji (2 soru) ve öz görünüm/sosyal etkileşim (2 soru) yer alır. Aile etkisi bölümünde iki tanımlayıcı alan ebeveyn sıkıntısı (2 soru), aile fonksiyonları (2 soru) yer alır. Likert ölçeği kullanılarak skorlanır: Hiç (skor o), neredeyse hiç (skor 1), ara sıra (skor 2), genelde (skor 3), çok sık (skor 4), bilmiyor (skor 5). ECOHIS, hem ağız sağlığı sorunlarının hem de bu sorunlarla ilişkili tedavi deneyimlerinin okul öncesi çocukların (3-5 yaş) ve ailelerinin yaşam kalitesi üzerindeki etkisini değerlendirir. Peker ve arkadaşları²3 tarafından 2011 yılında Türkçe geçerlik çalışması yapılmıştır.

\section{Sonuç}

Ağız sağlı̆̆ı, genel sağlıktan ayrılamaz bir bütündür. Ağız sağlığının genel sağlık üzerine etkisinin ölçülmesinde ağız sağlığına bağlı yaşam kalitesi ölçekleri kullanılmaktadır. Ağız bölgesinde görülen farklı sorunların değerlendirilmesi için çeşitli ölçekler tasarlanmıştır. $\mathrm{Bu}$ ölçekler sayesinde ağız ve diş hastalıklarının fiziksel ve psikolojik etkileri değerlendirilebilmektedir. Bu makalede, çocukların ağız sağlığına bağlı yaşam kalitesinin değerlendirilmesinde sıklıkla kullanılan ölçeklere yer verilmiştir. Ölçeklerin büyük bir kısmının Türkçe geçerlilik ve güvenirlilik çalışması yapılmış ve yaşam kalitesini değerlendiren çalışmalar için kullanılması uygun bulunmuştur. Ölçek seçiminde, yapılacak çalışmanın özelliğine uygun ölçeğin kullanılması çalışmanın sonuçlarının etkin bir şekilde değerlendirilmesi adına önemlidir. 


\section{KAYNAKLAR}

1. Higginson I, Carr A. Measuring quality of life: Using quality of life measures in the clinical setting. BMJ. 2001;322:1297-1300. doi:10.1136/bmj.322.7297.1297.

2. World Health Organisation. Global status report on noncommunicable diseases 2014.https://apps.who.int/iris/bitstream/handle/10665/148114/97892415648 54 eng.pdf?sequence $=1$ Erişim Tarihi 17.01.2021

3. Mean M. Oral health effects on quality of life. Dent Abstr. 2009;54(5):275-276. doi:10.1016/j.denabs.2009.06.041.

4. Baiju R, Peter E, Varghese N, Sivaram R. Oral health and quality of life: Current concepts. J Clin Diagnostic Res. 2017;11(6):21-26. doi:10.786o/JCDR/2017/25866.10110.

5. Locker D. Does dental care improve the oral health of older adults? Community Dent Health. 2001;18(1):7-15.

6. Bmi M, Control D, S-ecc T, Bmi B. Severe early childhood caries and obesity. Dent Abstr. 2017;62(3):163-164. doi:10.1016/j.denabs.2016.12.044.

7. Marcenes W, Kassebaum NJ, Bernabé E, et al. Global burden of oral conditions in 1990-2010: A systematic analysis. J Dent Res. 2013;92(7):592-597. doi:10.1177/o022034513490168.

8. James SL, Abate D, Abate KH, et al. Global, regional, and national incidence, prevalence, and years lived with disability for 354 diseases and injuries for 195 countries and territories, 1990-2017: A systematic analysis for theglobal burden of disease study 2017. Lancet. 2018;392(10159):1789-1858. doi:10.1016/So1406736(18)32279-7.

9. Jokovic A, Locker D, Stephens M, Kenny D, Tompson B, Guyatt G. Validity and reliability of a questionnaire for measuring child oral-health-related quality of life. J Dent Res. 2002;81(7):459-463. doi:10.1177/154405910208100705.

10. Jokovic A, Locker D, Tompson B, Guyatt G. Questionnaire for measuring oral health-related quality of life in eight-to ten-year-old children. Pediatr Dent. 2004;26(6):512-518. 
11. Paula JS de, Sarracini KLM, Ambrosano GMB, Pereira AC, Meneghim M de C, Mialhe FL. Impact of a dental care program on the quality of life of children with and without caries. Braz Oral Res. 2016;30(1):139. doi:10.1590/18073107BOR-2016.vol30.0139.

12. Çalık Yılmaz BC, Alaçam A. Çocuk algı ölçeğinin (cpq8-10) türkçe çevirisinin pedodonti kliniğinde geçerliğinin değerlendirilmesi. Atatürk Üniv Diş Hek Fak Derg. 2020;30(2):282-289.

13. Bekiroglu N, Bakkal M, Ozbay G, Karadeniz PG, Kargul B. Validity and reliability of Child Perception Questionnaire (CPQ11-14) by Rasch Analysis in Turkish children. Pediatr Dent J. 2017;27(1):14-20. doi:10.1016/j.pdj.2016.09.003.

14. Jokovic A, Locker D, Stephens M, Kenny D, Tompson B, Guyatt G. Measuring parental perceptions of child oral health-related quality of life. J Public Health Dent. 2003;63(2):67-72. doi:10.1111/j.1752-7325.2003.tbo3477.x.

15. Gherunpong S, Tsakos G, Sheiham A. Developing and evaluating an oral healthrelated quality of life index for children; The CHILD-OIDP. Community Dent Health. 2004;21(2):161-169.

16. Yusuf H, Gherunpong S, Sheiham A, Tsakos G. Validation of an English version of the Child-OIDP index, an oral health-related quality of life measure for children. Health Qual Life Outcomes. 2006;4:38. doi:10.1186/1477-7525-4-38.

17. Peker K, Eden E, Ak AT, Uysal Ö, Bermek G. Psychometric evaluation of the child oral impacts on daily performances (C-OIDP) for use in Turkish primary school children: a cross sectional validation study. BMC Oral Health. 2020;20(1):173. doi:10.1186/s12903-020-01162-y.

18. Broder HL, McGrath C, Cisneros GJ. Questionnaire development: Face validity and item impact testing of the child oral health impact profile. Community Dent Oral Epidemiol. 2007;35:8-19. doi:10.1111/j.1600-0528.2007.00401.x.

19. Broder HL, Wilson-Genderson M. Reliability and convergent and discriminant validity of the Child Oral Health Impact Profile (COHIP Child's version). Community Dent Oral Epidemiol. 2007;35:20-31. doi:10.1111/j.1600- 
0528.2007.0002.x.

20. Broder HL, Wilson-Genderson M, Sischo L. Reliability and validity testing for the Child Oral Health Impact Profile-Reduced (COHIP-SF 19). J Public Health Dent. 2012;72(4):302-312. doi:10.1111/j.1752-7325.2012.00338.x.

21. Tsakos G, Blair YI, Yusuf H, Wright W, Watt RG, Macpherson LMD. Developing a new self-reported scale of oral health outcomes for 5 -year-old children (SOHO-5). Health Qual Life Outcomes. 2012;10. doi:10.1186/1477-7525-10-62.

22. Pahel BT, Rozier RG, Slade GD. Parental perceptions of children's oral health: the Early Childhood Oral Health Impact Scale (ECOHIS). Health Qual Life Outcomes. 2007;5:6. doi:10.1186/1477-7525-5-6.

23. Peker K, Uysal Ö, Bermek G. Cross - cultural adaptation and preliminary validation of the Turkish version of the early childhood oral health impact scale among 5-6-year-old children. Health Qual Life Outcomes. 2011;9:118. doi:10.1186/1477-7525-9-118. 